\title{
The syzygy surfer: (Ab)using the semantic web to inspire creativity
}

\section{James Hendler}

Department of Computer Science and Cognitive Science, Rensselaer Polytechnic Institute (RPI),

Troy, NY 12180, USA

E-mail: hendler@cs.rpi.edu

\author{
Andrew Hugill* \\ Institute of Creative Technologies, \\ De Montfort University, \\ 1, The Gateway, \\ LEI 9BH, Leicester, UK \\ E-mail: andrewhugill@gmail.com \\ *Corresponding author
}

\begin{abstract}
This article discusses our development of a new web engine, the syzygy surfer, which aims to induce a search/browsing experience that is more creative than traditional search. We do this by purposefully combining the ambiguity of natural language with the precision of semantic web technologies. Here, we set out the framework for our investigation and discuss the context and background ideas that are informing the research. This paper offers some preliminary examples taken from our work in progress on the device and suggests the way ahead for future developments and applications.
\end{abstract}

Keywords: semantic web; search; pataphysics; panalogy; syzygy; clinamen; anomaly; creativity.

Reference to this paper should be made as follows: Hendler, J. and Hugill, A. (2013) 'The syzygy surfer: (Ab)using the semantic web to inspire creativity', Int. J. Creative Computing, Vol. 1, No. 1, pp.20-34.

Biographical notes: James Hendler is the Tetherless World Professor of Computer and Cognitive Science and Head of the Computer Science Department at RPI. He also serves as the Director of the UK's charitable Web Science Trust and is a Visiting Professor of Computer Science at DeMontfort University in Leicester, UK. He was the recipient of a 1995 Fulbright Foundation Fellowship and is a Fellow of the American Association for Artificial Intelligence, the British Computer Society, the IEEE and the AAAS. In 2010, he was named one of the 20 Most Innovative Professors in America by Playboy magazine.

Andrew Hugill is the Director of the Institute of Creative Technologies (IOCT) at De Montfort University, Leicester, UK. He is the author of The Digital Musician (Routledge, 2008) and The Origins of Electronic Music in 'The Cambridge Companion to Electronic Music' (Cambridge University Press, 2007. In his capacity as the Director of the Institute of Creative Technologies, he leads various collaborative projects, such as: digital mapping, technology and disability, virtual heritage, and human creativity. He is the author of Pataphysics: A Useless Guide (MIT Press, 2012). 


\section{Introduction: creative uses of the web}

Ever since the web was invented, it has been used to expressive ends by creative people. Apart from the enormous growth in the sharing of offline content, there have been many attempts to use or originate novel online technologies. In this paper, we will focus on creative interactions between user and web, and not between users connecting through the web. A large amount of the time spent on the web nowadays is for the social 'Web 2.0' of Facebook, twitter, gaming, virtual worlds, etc. There is much to be said about the relation between the social web and creativity, but in these environments the user is primarily involved in interacting with other people, and not directly with the linked information content of the web itself.

The artistic end of interaction with the web is known as 'web art', and has emerged from the earlier tradition of 'net art'. Both forms are of course relatively new compared to the more established traditions of art, with a history measured in decades rather than centuries. Bosma (2009) suggests five main phases:

"We now see the fifth generation of artists who work with computer networks. Of these five generations four worked with the internet, and one (the first) worked with forerunners of the internet."

What characterises the best net and web art is a highly creative approach to the medium itself. Sometimes this has led to real technological innovations, but often it generates content that is fairly ephemeral. As Bosma (2010) observes:

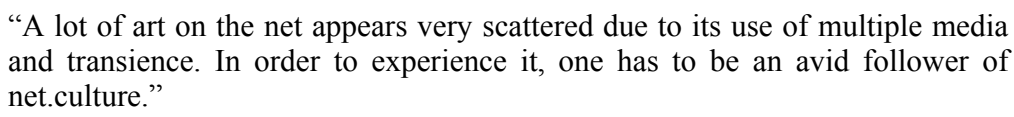

"A lot of art on the net appears very scattered due to its use of multiple media and transience. In order to experience it, one has to be an avid follower of net.culture."

But creative uses of the web are not the sole province of 'artists' as such, and may extend into self-expression as an aspect of personal or cultural identity, in a more utilitarian context or indeed in gaming. Creative users of the web may find amusing ways to abuse (or, more politely, creatively experiment with) the technology, as artists have always done, but in the vast majority of cases the limits of such fruitful play are set by software engineering. A typical example of a piece of web art, such as Inanimate Alice, (Pullinger and Joseph, 2005) skilfully and beautifully deploys many of the currently available web technologies in both its creation and expression to produce a rich and satisfying artistic outcome with which users may interact. However, the web itself has been used purely as a tool in this process, and has made little or no creative contribution of its own.

\section{From surfing to search}

Although the web may be used for creative pursuits, the typical interaction between a user, artist or otherwise, and the web is generally not supportive of creative endeavours. This is somewhat ironic because, in the early days, using the World Wide Web was all about serendipity and creativity in a way that has been largely lost as it has grown and been commercialised. Early on, coming to the Web was a voyage of discovery, aimed at tracking how things connected, rather than just what they were about. As Tim Berners-Lee, the inventor of the web, recalled in a 1994 interview: 
"I found I needed [the web] just to keep track of the - how shall I say flexible? creative? - way new parts of the system, people and modules were added on and connected together." (Berners-Lee, 1994)

Users who downloaded the early browser-prototypes would go to some starting place on the web, such as Cern's TheProject.html ${ }^{1}$ and start exploring. Much of the joy of the web was finding new and different things one did not know existed. With websites being few and far between, the joy was often in the serendipitous discovery of a new area or technique that one did not know existed. To provide a metaphor for this interaction, in an article in 1992 Jean Armour Polly introduced the term 'surfing' to refer to the act of interacting with the web. In explaining the choice of this term she wrote:

"I weighed many possible metaphors. I wanted something that expressed the fun I had using the internet, as well as hit on the skill, and yes, endurance necessary to use it well. I also needed something that would evoke a sense of randomness, chaos, and even danger." (Polly, 1992)

In short, the journey on the web was about discovering what was out there not on finding specific content.

This changed as the web grew. Early software, especially Mosaic, the first really popular web browser, created a feature we now call 'bookmarks' so people could make a note when they found a site they would like to go back to. To reduce the frustration of trying, often fruitlessly, to get back to a page one had previously discovered, the software would remember the link, putting it into a list that you could click on to go directly to that site. The 'randomness, chaos and even danger' was replaced by a direct link to your content of choice, usable repeatedly.

Even this, which required finding ones way to a destination became frustrating as people expected more and more information to be available on the web. By the mid-' 90 s there was a clamour for a way to find content that one needed to pursue a task, explore an interest, or otherwise use the web productively. The lower effort needed to produce web pages, and the many more entities (especially commercial) interested in doing so, led to way more content being available. However, it also seemed to lead to less average value in what one might find. A random jump into the web would no longer take one somewhere exotic; rather than hitting on new and exciting content at every turn, much of the content seemed mundane and irrelevant. Much time could be 'wasted' by surfing through the inane and mundane, rather than finding one's way to novel and interesting content.

To combat this, by the mid-1990s Altavista, the first successful search engine was born. Users could now ask for pages on a particular subject or person, and the search engine would try to minimise the effort found in getting to something highly related. Soon, as the web continued its exponential growth, new search engines came along, and by 1998 a search engine called backrub, created by some Stanford students and later renamed 'Google' started to take over access to the web. By the early part of the 2000s, Google became the corporate monolith that determined most people's access to the World Wide Web. In fact, most users do not even realise that the web was originally designed to 'browse' and 'explore', surfing has become a term for the secure journey to a well-regarded site full of safe (by the user's own standards) content.

We certainly do not wish to imply that search is not necessary to the web, nor that the capabilities for discovery inherent in a search engine are not useful to creative technologists. However, it is undeniable that search technology has reduced the 
serendipitous discovery of new information that was the original hallmark of the web. Hitting on a page that will provoke new and different ideas has become a matter of knowing where to look, not one of random encounter. In fact, entire technology areas, such as the recommender systems that are used by large online merchants ${ }^{2}$, have grown out of an effort to help people find other things than they might be looking for, to replace the sort of browsing that might take place in a bookstore or museum, where discovery of something previously unintended is a major goal.

The reason for this lies in the problem of too much information being available. A user who knows what they are looking for cannot be expected to sift through the entire web in order to arrive at their intended destination. Consequently, the opposite scenario, in which a user does not know, nor even wish to know, what they seek, has largely been eliminated. Imagine yourself in a vast library without a catalogue. How can you navigate the collection? And how much more could be achieved if you are a creative user and the tool you used to help you navigate enabled a series of connections or links that made inspirational, rather than logical, sense!

\section{A return to creativity}

Harnessing the creative intelligence of the web provides the potential for a new way of working, one in which its semantic content is able to interact in effective dialogue with the user in order to throw up creative ideas. The applications of this tool could be to the origination of artworks, but also to challenging areas such as browsing rich data collections (e.g., large libraries, media archives, and so on). What is required is a tool which engages with the user's subjectivity in a way that is uniquely personalised and yet intelligent in itself, purposefully purposeless, capable of operating a creative loop that is dynamic yet exhibits a sense of underlying poetic unity. In other words, the web could become the ideal creative partner if only it understood better what you want, what you mean, what you need, and, more, was able to come up with things you did not realise you want meant, or needed, but were pleased to discover when you found them.

Imagine the boon to creativity should the web be able to provide the happy accident, the increasing return, the re-contextualisation, the contradiction, the breakdown and recovery, the 'aha!' moment, the tilt and shift, the turn-it-over-and-see-it-another-way, the vibe, the buzz, the daydream, the wonder and the wander, the aesthetic, the history, the sweat and repetition, the excess and bravado, the originality, the skill, the virtuosity, the meaning and the meaninglessness that are the stuff of any creative process. However, to do this the web needs to be able to do the opposite of what it is currently evolving to do, which is to deliver ever-more-targeted results underpinned by commercial interests. It needs to be able to take the user off in new and surprising directions and to do that consistently in ways that are useful from a creative viewpoint, which of course will differ from person to person. This was part of the original vision of the founders of the web, yet is something that is increasingly being lost as the technology continues to 'improve'.

What would be the requirements of a creative technology, a surfing (not search) engine for the creative technologist? Firstly, simple randomness will not be enough. Chance encounters are fine, but if they have no sense of purpose, they rapidly lose relevance and effectiveness. The key is to retain the element of surprise while at the same time avoiding a succession of complete non-sequiturs and irrelevant content. What is 
required, instead, is an underlying poetic sense of unity. Consider this quotation from Jorge-Luis Borges' story The Analytical Language of John Wilkins, which describes 'a certain Chinese Encyclopedia', the Celestial Emporium of Benevolent Knowledge, in which it is written that animals are divided into:

- those that belong to the Emperor

- embalmed ones

- those that are trained

- suckling pigs

- mermaids

- fabulous ones

- $\quad$ stray dogs

- those included in the present classification

- those that tremble as if they were mad

- innumerable ones

- those drawn with a very fine camelhair brush

- others

- those that have just broken a flower vase

- those that from a long way off look like flies.

If the web could categorise resources into categories such as these, and deliver a set of responses that could deliver this level of charming surprise, and in a way that is creatively useful, then we have a tool which artists will really value.

\section{Creative knowledge on the web}

Making a categorisation like Borges' cannot be done via statistical regularity nor can it be achieved using traditional categorical knowledge. Rather, it seems that we need something that can permute knowledge about the regularities in the world, but in a not-totally-random fashion - we must exploit connections among concepts in a new way so as to generate relations that seem interesting, but unusual.

In traditional web engineering, the most successful of many attempts to bring some sort of knowledge to the web has been via the use of what has become known as the semantic web technologies. The semantic web allows us to create machine-readable annotations that can be used in defining relationships between items on the web. These relationships are generally encoded either through tags on the web pages themselves or as statements about items on or off the web. The term 'metadata' is often used to describe the information about data resources that is not encoded directly in the data itself, and thus the semantic web, which describes these relations between data resources on the web, is essentially a means for bringing a rich level of metadata to the web. 
The languages of the semantic web provide some relatively simple metadata relationships directly, such as defining one class of objects to be a subclass of another, or for encoding some facts about a relationship that is to be defined between two objects (i.e., providing metadata about the relation being named). An example of the first could use a built in function to state that if something is a 'graduate student' then it is also a 'person', the second could be used to create a named relation called 'AdvisorOf' which can be defined to relate a 'student' to a 'facultyMember'. A collection of such statements, which can also include specific examples of things named by these relations (i.e., that the web location named 'http://www.cs.rpi.edu/ hendler/foaf.rdf\#me' denotes a 'facultyMember'), is called an 'ontology'. The items in an ontology are generally assumed to be of things related to each other in some domain, although that is not necessarily the case.

In using these technologies on the web, the ontologist, that is the person making the categorisation, must decide in advance how things will be grouped. Thus, for example, if one wanted to create a description of a number of recipes, and to define which ones were vegetarian the designer must decide where to put milk, eggs, fish and other controversial items. So where a vegan would want a recipe with cheese to be excluded from this category, some other user might not. On the other hand, to the pescatorian, the salmon with goat cheese should be grouped with the vegetarian foods. The ontologist can get around this problem by creating multiple categories - ovo-lacto, fish-included, etc. - but there still must be a decision made as to what to call all these categories, or to not include a hierarchical distinction, thus losing the ability to distinguish the dishes which include traditional meats from the ones which do not. Thus, the ontologist decides, a priori, what categories and relationships will be included in the categorisation.

Table 1 Borges' definitions of animals, annotated

\begin{tabular}{lc}
\hline Class & Relations \\
\hline Those that belong to the Emperor & Culturally specific, royal, possessive \\
Embalmed ones & Past, preserved \\
Those that are trained & Made uniform, commonalities \\
Suckling pigs & Young, edible, noisy \\
Mermaids & Seductive, semi-human \\
Fabulous ones & Mythical, imaginary \\
Stray dogs & Outside known networks, rough and ready \\
Those included in the present classification & Organised, self-similar \\
Those that tremble as if they were mad & Uncontrolled, incoherent \\
Innumerable ones & General, multiple \\
Those drawn with a very fine camelhair brush & Culturally specific, aesthetically distinct \\
Others & Non-categorical, unspecifiable \\
Those that have just broken a flower vase & present, errant, mischievous \\
Those that from a long way off look like flies & swarming around a particular topic \\
\hline
\end{tabular}

However, the ontologist is not constrained to use categories and relations that are this simple, in fact one could use, for example, the fourteen classes from Borges as the categories in an ontology and define a sorting of objects into these. ${ }^{3}$ More challenging, 
however, would be defining the sorts of relations that would cause us to decide which objects might go into these classes. Consider Table 1, where we expand Borges' Chinese encyclopaedia looking at some examples of the evocative relations that the categories depend on. Stating that these relationships exist is non-problematic, but defining the features of them unambiguously would be arbitrarily hard.

This leads us to the essential contradiction that the use of web knowledge for creativity requires us to overcome: the obviously creative categorisation of Borges is difficult, if not impossible, to directly build in such a way that a web system, reasoning using these, could do its job. Drucker (2009. p.7) makes the same point forcefully:

"Humanists are skilled at complexity and ambiguity. Computers, as is well known, are not. The distinction amounts to a clash of value systems in which fundamental epistemological and ideological differences arise."

It is our contention, however, that this dichotomy can be used to enable the sort of creative encounter on the web that we are looking for. The trick is to find precise, unambiguous algorithms that the computer can apply to the growing metadata-based knowledge on the web, but which when realised can enable a human to envision the existence of relationships that the machine would not be to represent or use directly. This behaviour, properly done, should enable the machine to produce a non-random encounter that the human may see as either logical or surprising or both, but which will let the human conceptualise the inherent ambiguity that the machine is incapable of directly creating.

\section{The syzygy surfer concept}

Our prototype of this kind of 'creative encounter engine' generates the ambiguity described above by combining an idea from a philosophical tradition that is particularly human and unlikely to be representable on the machine at any time in the foreseeable future with a technical architecture that was designed specifically as a mechanism for representing on a machine much-more-human cognitive behaviours. The philosophical tradition in question is pataphysics ${ }^{4}$, which is both a set of ideas and an attitude of mind. As the playwright Eugène Ionesco commented [McMurray, (2001), p.124]:

"It's the spirit of pataphysics that's grabbed me, and it's through the spirit of something that one draws inspiration from it."

The term 'pataphysics ${ }^{5}$ was coined by Alfred Jarry (1873-1907) to describe "the science of that which is superinduced upon metaphysics, whether within or beyond the latter's limitations, extending as far beyond metaphysics as the latter extends beyond physics [Shattuck and Watson-Taylor, (1965), p.192]. It is further defined as "the science of imaginary solutions" (Jarry) and resting on "the truth of contradictions and exceptions." (Raymond Queneau). It is underpinned by a science of the particular that substitutes a thoroughgoing subjectivity for the universal axioms of physics, or the logic of metaphysics. In this pataphysical universe, mutually exclusive opposites can and do simultaneously exist, and can merge together.

"If you let a coin fall and it falls, the next time it is just by an infinite coincidence that it will fall again the same way; hundreds of other coins in other hands will follow this pattern in an infinitely unimaginable fashion". (Jarry) 
We contend that certain pataphysical tropes are relevant to the ways in which a creative encounter engine might operate:

- Syzygy has its origins in astronomy, where it denotes a moment of alignment of three or more celestial bodies, such as in an eclipse. Unexpectedness or surprise is a feature of syzygy, probably because of its origins in a time before such events became predictable. In pataphysics, the 'syzygy of words' provides the path to pataphysical humour, which is 'born out of the discovery of the contradictory'. In a letter from God, Dr. Faustroll notes "a small fragment of the beautiful that he knew, [...], and a small fragment of the True;" from which "one could have constructed [...] all art and all science". (Jarry, p.245)

- The idea of Clinamen is an example of an imaginary solution, since Epicurus (341-270 BC) had little or no experimental evidence apart from human experience on which to base his theorising. The Epicurean universe consists of atoms in continuous descent from an absolute high to an absolute low. During their descent, for reasons we cannot know or understand, some of the atoms happen to make a slight swerve or bias (the 'clinamen') in their trajectory, causing them to collide with other atoms. These chain reactions create matter. Human freedom, according to Epicurus, is a direct result of these indeterminate motions of atoms.

- Anomaly is probably the most generally familiar of the themes of pataphysics (although not specifically as a 'theme of pataphysics', of course), not least because it has been the subject of continuous and thorough popular documentation. ${ }^{6}$ However, we must resist the crude conclusion that pataphysical anomaly is the same thing as "the paranormal". In pataphysics, there should in theory be no possibility of anomaly, since everything is equally exceptional. The pataphysical anomaly, therefore, exists within the rules that it apparently contradicts. Georges Perec summed it up in this short quasi-syllogism: "if physics proposes: "you have a brother and he likes cheese", then metaphysics replies: "If you have a brother, he likes cheese". But "pataphysics says: "You don't have a brother and he likes cheese". [Perec, (1968), p.52]

Syzygy, clinamen and anomaly are pataphysical methods that offer the kinds of decelensions we seek. They are the stuff of ambiguity, since they constantly undermine in a non-destructive way whatever logic pervades at a given moment, yet they are scientific in nature. In providing a ludic response to supposedly serious situations they introduce just that charm and jouissance that is required for creative engagement.

Since the semantic web's metadata is based on exactly the avoidance of this kind of inconsistency and ambiguity, we require a new approach in order to make syzygy surfers of the users. Once again, pataphysics provides a perfect imaginary solution. As pataphysics is to metaphysics as metaphysics is to physics, so we can consider what lies beyond metadata to be patadata. In thus envisaging a layer of meta-metadata, we will benefit from the ambiguities thrown up by the process of metadata creation, precisely those 'shortcomings' identified by Doctorow (2001) in his 'Metacrap' thesis: ' lying, laziness, error, subjectivity, plurality, and so on. But we will also be able to insert our pataphysical declensions into the metadata harvest in a way that will enrich the creative interaction, rather than just deliver a series of obvious mistakes. 


\section{Panalogy as a mechanism for patadata}

We draw our technical inspiration from the concept of panalogy (parallel analogy) put forth by Push Singh and Marvin Minsky. The idea behind panalogy, somewhat simplified for the sake of this discourse, is that our understanding of any object or action cannot easily be explained in any single conceptualisation, For example, if we are looking at a table, we can see it as furniture, as something with legs, as something to eat off, etc. In each of these cases, we may wish to have different hierarchies of classification: furniture with respect to cost and design, legged entities with respect to animate or inanimate, eating as one function among many, and so on. Thus, the concept 'table' is not wholly defined in any one ontology, but rather as some sort of pananalogy between many. As Minsky explained it in his book The Emotion Machine:

\footnotetext{
"The Panalogy Principle: If you 'understand' something in only one way then you scarcely understand it at all-because when something goes wrong, you'll have no place to go. But if you represent something in several ways, then when one of them fails you can switch to another. That way, you can turn things around in your mind to see them from different points of view -until you find one that works well for you now. And that's one of the things that 'thinking" means!"” (Minsky, 2006)
}

The last piece of the puzzle, which would at one time have been the hardest to figure out, is: how to develop the many representations, and links between objects in them that the panalogy approach demands. In recent years, as the semantic web technologies have grown in use, a great many ontologies have in fact been defined, many of which are quite broad and span many terms, but others of which are fairly specific. Currently, there are several millions of documents on the web that contain some kind of ontological information. This number is now growing rapidly as major companies such as Microsoft, Google, Facebook, and Twitter are now using or encouraging the use of semantic tagging on the web. Thus, finding the same concept represented in many different ways for exploring panalogy is enabled by the semantic web.

\section{Putting it all together: the syzygy surfer}

Most human words are ambiguous and contain several possible meanings or embody a number of concepts. Thus, for example, while we can find semantic web files which define 'tables' as furniture in common terms relating to form and function, the word 'table' itself also produces other kinds of tables, such as the periodic table, water tables, table segmentation faults (in computer operating systems) and many more. Each of these, in turn, may be found in several ontologies. By linking the representations of different kinds of tables together, based on the word meanings, we can create what is essentially a creative panalogy. Figure 1 shows an example for the word 'table':

In combining the ambiguity of language with the precision of semantic web ontologies, such creative panalogies will deliver patadata. Thus, a panalogy may become a way to conceptualise a computational model for introducing ambiguity, because the same object may be formally ontologised in a number of ways. The ambiguity of experience is the hallmark of creativity that is captured in the essence of pataphysics. Traversing the representations of this ambiguity using algorithms inspired by the syzygy, clinamen and anomaly of pataphysics, using a panalogical mechanism applied to 
metadata, should be able to humanise and even poeticise the experience of searching the web.

Figure 1 A 'creative' panalogy is made by combining ambiguous language with precise representation (see online version for colours)

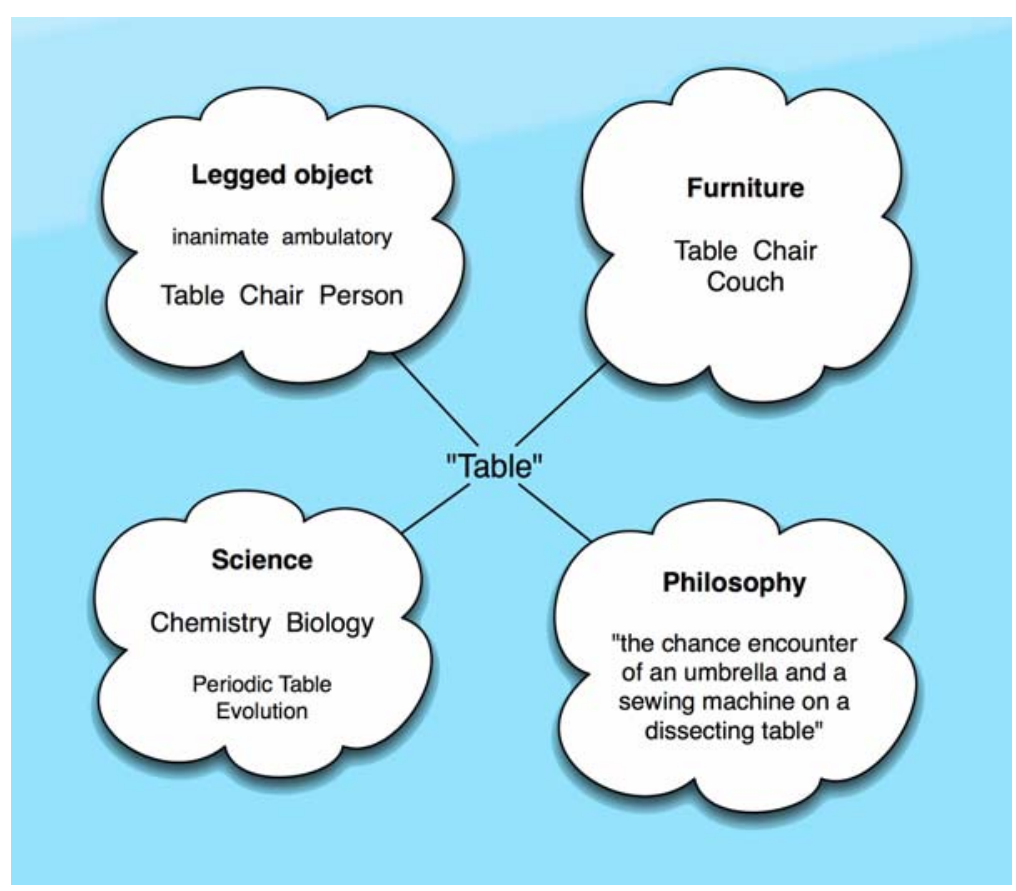

The syzygy surfer, therefore, works by taking input from a user and generating a panalogic patadata structure for each entry. Pataphysical concepts such as syzygy, clinamen, and anomaly, are then applied to vary the user's terms into a 'creatively related' search. Let us examine how this works in the (rather uninspiring) example given in Figure 1.

The syzygy of 'table' relies on the accidental alignment of multiple concepts. We simulate this idea by taking terms related to the target term from each of several ontologies, and then using the combination of terms to generate a search. Thus, from 'table' we could end up looking for a document that includes chair, periodic-, and dissecting. These are fed to a traditional text search, and it produces documents such as The Tom Lehrer song about the periodic table of elements, a blog entry in which author James Howard Kunstler 'dissects' modern life in suburbia, and the web page for the US national clearinghouse for management of squamous cell cancers.

The primary idea behind the clinamen is that of an atom 'swerving' in its path. This notion of swerving has been used by a number of writers to explain what they do. For example, Harold Bloom used the notion of the clinamen to explain the inclination of writers to invent new forms rather than to follow the ways of their predecessors (Bloom, 1973). An extreme case of such moving from the ways of the predecessors is seen in 'pataphysics in the work of the Ouvroir de littérature potentielle (Oulipo), which would use various techniques to generate literature based on constraints outside the norm. One 
constraint used by the Oulipo is that of $\mathrm{S}+7$, which works by replacing words in a sentence with other words that occur seven definitions later in some dictionary. We couple this idea with the web search not by taking the words from some other dictionary, but from other descriptions of the term being searched for in other ontologies. The approach we use is to take a partial description of the thing being searched for in one ontology, and to replace several of the words (chosen at random) with the corresponding words from definitions found in other ontologies (after removing a number of simple common words such as 'a', 'the', 'of', etc.). Thus, using a clinamen for 'table' we could take a definition such as "an abstract, a table of contents, a graphical representation," (found in http://dublincore.org/2010/10/11/dcterms.rdf) and end up with the phrase 'hierarchical anthophyllite visually, ebony water' which, when fed to a search engine, produces results ranging from a small company in New Jersey to the search history from a Shanghai-based search engine.

Anomalous 'tables' are made from the negation of the topic. We model this by searching for documents that do not include related terms. From the panalogy, we can see that 'table' is commonly related to furniture, to science, to philosophy, to legs, etc., so we search for the occurrences of table that are missing these common referents. This leads to topics such as the HTML TABLE construct, the ASCII table, a book called The Table, and a video on table tennis.

We note that there is no guarantee that any particular term used in any one of these operations will necessarily produce a search result. When we get a null result we have a number of options that the algorithm can take - given the randomness in choices of both operations and to the results within the panalogy as to which terms we extract, we make use of a technique known as backtracking (saving decision points and making a difference choice when one leads us to a dead end) and find our way to a result. In the rare case that there is no ontology or semantic document that corresponds to the term, we produce a standard search result and continue.

These patadata operations can also be applied in combination with each other. Thus, for example, for 'table' we can combine syzygy and anomaly to produce the search string:

$$
\text { table chair periodic dissecting - furniture - chemistry - surrealist }
$$

Feeding this into a search engine (US Google, October 2010) produces among its top results a blog page in which someone describes his most memorable experience in high school (when a girl pulled the chair out from under him in a biology class while dissecting a fetal pig, causing him to overturn some lab tables), the web page for B\&M Scientific equipment suppliers, a page about Siddhadreams (the father of ancient Indian Chemistry) and images including one of donkey's face and the poster from the play Wicked.

Now let us consider some rather more creatively inspiring examples. Figures 2, 3 and 4 show some of results we get using these operations - we take terms from Borges' Chinese encyclopedia and show what is produced by applying the patadata principles (we are not yet generating these results automatically, but we use only the search operations described here). 
Figure 2 Syzygy on 'fabulous' (see online version for colours)

\section{Fabulous: Syzygy}
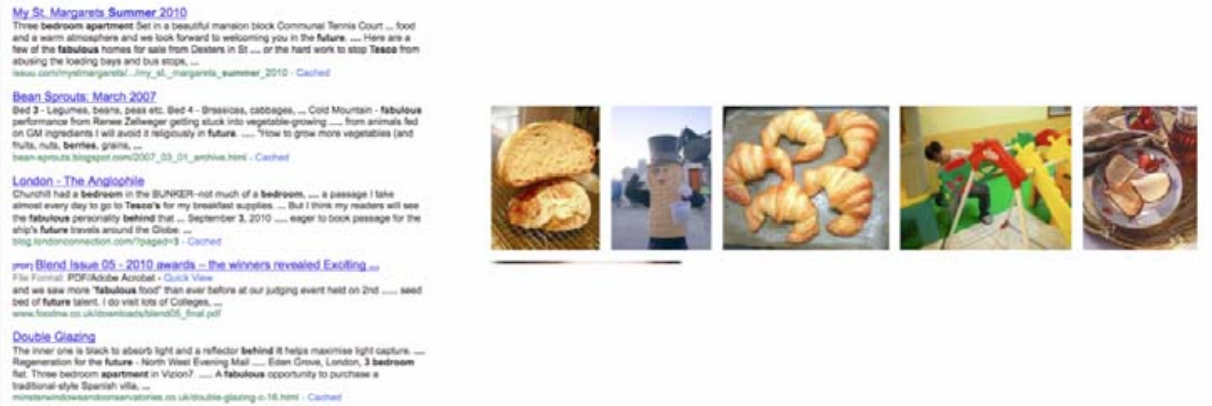

Figure 3 Clinamen on 'mermaid' (see online version for colours)

\section{Mermaid: Clinamen}
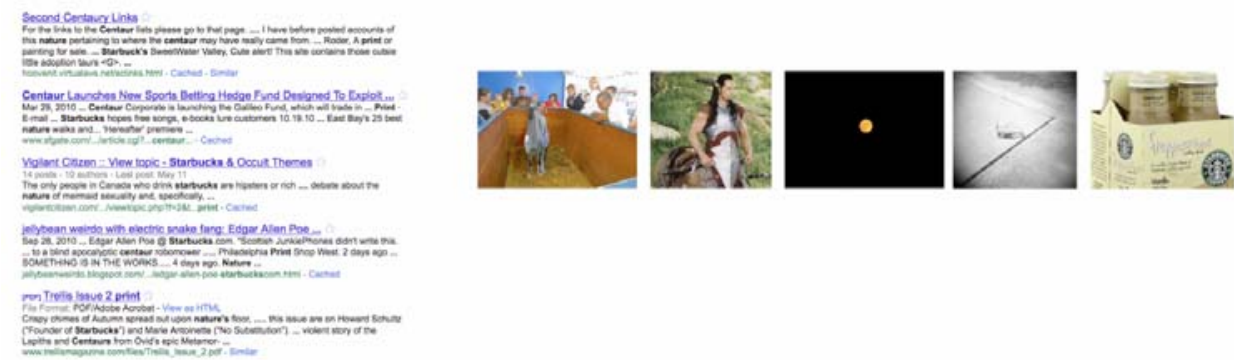

Figure 4 Anomaly on 'trained' (see online version for colours)

\section{Trained: Anomaly}
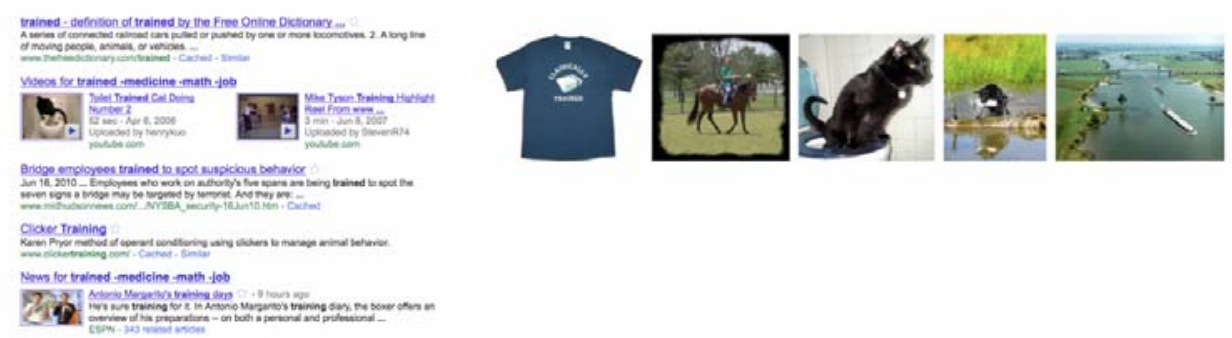


\section{Implementation and future research}

We are currently implementing this algorithm both for the open web (where we will use the results of a commercial search engine as the basis for our searches) and in a domain dependent way, aimed at exploring large collections such as the holding of the British Library or the Institut National Audiovisuel Français, where we can preprocess many of the terms and relationships for an efficient search and to be sure that the results remain surprising but useful.

Interface design will be an important aspect of the finished syzygy surfer. Our early thoughts about this rest on a few guiding principles: the user should be able to choose the techniques they use; the system will suggest terms that the user could add or change in their searches; there should be a 'breadcrumb trail' of navigation, so that users can readily find their way back to a previous instance; the look and feel should reflect the underlying workings of the engine, but at the same time be attractive, accessible and adaptable.

Pataphysics itself has a rich symbology that provides a useful starting-point for all these aspects. In particular, the form of a spiral, suggesting continuous evolution, gives an unusual appearance to the design. Some early sketches for this include Figure 5, below, which shows a three dimensional representation with each granular element representing an individual 'search' and the vertical stacks representing several alternative versions of the same instance.

Figure 5 Syzygy surfer - preliminary interface design

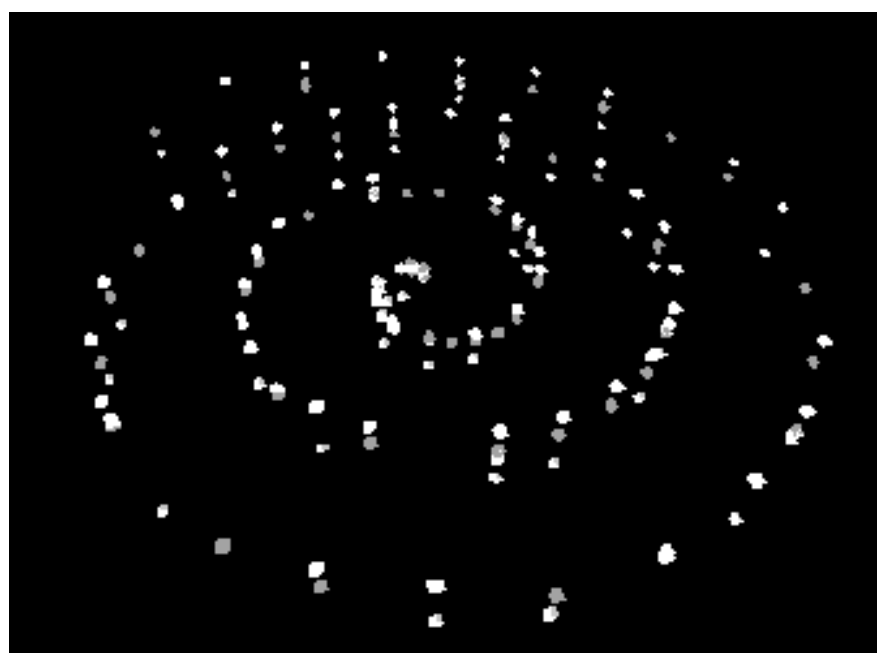

Each element may itself be clicked, leading to a further potential spiral of similar design. Hovering over an element will reveal the text strings used to create that particular search. Colours may be ascribed to the elements by the user to classify them within given ranges, such as: like/dislike, hot/cool, rich/poor, exceptional/unexceptional, particular/general, etc. Thus, the subjective "universe supplementary to this one" (Jarry), may be constructed by the user during his/her meanderings. At any point, the possibility of an exception will exist, not just because (as the cliché runs) "it is the exception that proves the rule", but 
rather because, as Bök (1996, p.39) observed: “[...] the rule itself is the exception in a pataphysical science that rules out the rule."

\section{Conclusions}

We have described the concepts underlying the development of a new web application, the syzygy surfer, which aims to induce a search/browsing experience that is more creative than a traditional search. We do this by purposefully combining the ambiguity of natural language with the precision of semantic web technologies. Using concepts from the pataphysical literature, we have developed methods in which terms in semantic web ontologies are used in new ways to purposely create and exploit ambiguities so as to yield novel, but non-random, results. We achieve this by treating multiple meta-data-based ontologies as a panalogy, combining them into patadata. This paper offers some preliminary examples taken from our work in progress on the application.

\section{References}

Berners-Lee, T. (1994) Interview with Kris Herbst in Internet World, from Tim Berners-Lee [online] http://www.w3.org/People/Berners-Lee/FAQ.html (accessed 16 October 2010).

Bloom, H. (1973) The Anxiety of Influence: A Theory of Poetry, 2nd ed., 10 April 1997, Oxford University Press, USA, ISBN: 0195112210.

Bök, C. (1966) Pataphysics: The Poetics of an Imaginary Science, 2002 ed., Northwestern University Press, Illinois.

Bosma, J. (2009) 'Radical diversity - the confluence of art and the internet', 3rd Inclusiva-Net Meeting, Inclusiva-Net, Buenos Aires.

Bosma, J. (2010) 'Is it a commercial? Is it spam? It's net art!', laudanum.net [online] http://laudanum.net (accessed 21 October 2010).

Doctorow, C. (2001) 'Metacrap: putting the torch to seven straw men of the meta-utopia' [online] $\mathrm{http}: / /$ www.well.com/ doctorow/metacrap.htm (accessed 06.08.2012).

Drucker, J. (2009) SpecLab: Digital Aesthetics and Projects in Speculative Computing, University of Chicago Press, Chicago.

McMurray, L. (2001) 'Interview with Eugène Ionesco', in Quatre leçons et deux devoirs de pataphysique, Liber. Translated from the French by Mark Mason, Montréal.

Minsky, M. (2006) The Emotion Machine: Commonsense Thinking, Artificial Intelligence, and the Future of the Human Mind, Simon \& Schuster, New York [online] $\mathrm{http} / / /$ web.media.mit.edu/-minsky/ (accessed 10.09.2012).

Perec, G. (1968) Qu'est-ce que la pataphysique? Radio-Sarrebrück interview, cited in Collège de 'Pataphysique, (1968 vulg., June 15). Subsidia Pataphysica, 7.

Polly, J.A. (1992) 'Surfing the internet 1.0', in Wilson Library Bulletin, June.

Pullinger, K. and Joseph, C. (2005) Inanimate Alice, from Inanimate Alice [online] http://www.inanimatealice.com (accessed 16 October 2010).

Shattuck, R. and Watson-Taylor, S. (Eds.) (1965) Selected Works of Alfred Jarry, Methuen, London. 


\section{Notes}

1 A copy of the 1992 version of this page can be found at http://www.w3.org/History/19921103hypertext/hypertext/WWW/TheProject.html.

2 Recommender is the technical term for the technology underlying the sites where one sees content such as 'people who bought this book have also bought' and the like.

3 Actually, the categories 'those included in the current classification', 'others' and 'those that have just broken a flower vase' would cause some technical issues if we wished to give them their natural meanings, but we will ignore these details as they are not germane to the points being raised in this paper.

4 Johanna Drucker and the team at University of Virginia's SpecLab have also adopted 'pataphysics as the driving force in their work on digital humanities research methods.

5 The use of the preliminary apostrophe was initiated by Jarry 'to avoid an obvious pun'. The convention is that its use only applies to conscious 'pataphysics and it is therefore omitted in the generalised form.

6 Nothing, it seems, is so fascinating as the thing that does not fit. For example, The Sourcebook Project of William R. Corliss (b. 1926), begun in 1974 and continuing to accumulate examples (over 40,000 to date), sets out to catalogue in a non-sensationalised way 'unexplained phenomena' in science, archaeology, geophysics, geology, astronomy and other areas.

7 From a pataphysical point of view, the thesis is appropriately named, given the famous first word of Jarry's Ubu Roi: 'Merdre'. 